\title{
New Illustration for Creating of the Orchid Pavilion of Yu Wenhua's Version from Aesthetic Perception
}

\author{
Guangzhuang $\mathrm{Yu}$ \\ School of Music \\ Anshan Normal University \\ Anshan, China
}

\begin{abstract}
The Orchid Pavilion, also called Xi Tie, was written in $353 \mathrm{AD}$ the ninth year of Yonghe under the reign of Emperor $\mathrm{Mu}$ in East Jin Dynasty. It is a noted calligraphy that records astonishing scenes surrounding the Orchid Pavilion on Shanyin and the great joy of gathering to party. Meanwhile, it fully expresses thoughts of Wang Xizhi about the unexpected changes that would happen for human life and death. The Orchid Pavilion moves numerous Chinese descendents by its delicate content and refined writing system. Yu Wenhua combines this masterpiece with modern vocal music to create a special piece of musical work, which is also propagation for Chinese ethic calligraphy. This thesis analyzes the main ideology, the creating process and practical meaning of the Orchid Pavilion from the aspect of aesthetics.
\end{abstract}

Keywords-the Orchid Pavilion; Yu Wenhua; aesthetic perspective; new comprehension

\section{INTRODUCTION}

As a magnificent nation, China has long been a place full of music ever since the ancient times, there are lots of creations that are widely disseminated and never stopped spreading. Music not only appreciated as an elegant artistic form, also acts as a tool for artists to express their feelings [1]. During the process of criticizing Chinese traditional culture after the founding of People's Republic of China, ancient poems and music are endowed with modern cultural style and becomes a new trend of music composing. So far, many great musicians accumulate ancient poems and restore some of the lost, broken or the sole copy of these compositions, and then they write notes to match them. The Orchid Pavilion is applied by Chinese soprano $\mathrm{Yu}$ Wenhua to combine with high-pitch musical notation for the composition of her song. The Orchid Pavilion is a famous piece of work written by Wang Xizhi, who is a great calligrapher in East Jin Dynasty. The song soon attracted a large number of listeners by its peculiar and familiar content and its modern musical style.

\section{THE COMPOSING BACKGROUND AND THEME OF THE ORCHID PAVILION}

As a transcript for a preface, the Orchid Pavilion is written in the ninth Yonghe Year under the reign of Emperor $\mathrm{Mu}$ in East Jin Dynasty. The whole work is composed of 28 lines with 324 characters in it. It is a perfect combination of essay and calligraphy, a classic model of content and format. This is the work of Wang Xizhi, a great calligrapher in East Jin Dynasty. He combines the merits of Li, Cao, Kai and Xing and breaks away from writing style popularized in Han and Wei Dynasty, thus this transcript becomes "the most terrific handwriting under heaven" according to calligraphers in all times. The Orchid Pavilion is written when Wang was on his trip to Zhejiang Province for the first time, and is a narrative of the party held in the Orchid Pavilion of Shanyin county, and the party was attended by many intellectuals such as Xi An, Sun Zhuo. Literary attended all create poems and express their abundant inner world at the party, and their works are copied and Wang is invited to write a preface for this transcript and then the Orchid Pavilion came out [2]. The theme of the Orchid Pavilion seems to be the description for enjoyable scenery of mountains and rivers surround the Pavilion at the first glance, and the pleasant emotions of each intellectual and celebrity at the graceful party. While indeed, it is Wang's exclamation for the fugacious of life and capricious of death.

\section{AESTHETIC FEATURE OF YU WENHUA's VERSiON OF THE ORCHID PAVILION}

\section{A. Combing Aspirations and Thoughts of the People and Emphasizing Calligraphic Structure}

Strong ethical complex functioned in the whole process of Yu Wenhua's musical creating. She is deeply interested in folk music and this hobby of hers stands as her lighthouse in her artistic works. She holds that notes used in folk music should highlight the application of romantic charm as it exists in literatures. She believes the importance of digging into essence of music and thus realize the thoroughly utilize and combination of romantic charm with creative spirit into the composition of folk music. The Orchid Pavilion is a superior work in both literary content and calligraphy, especially its writing style, its structure and the organization of the essay. For instance, Huang Tingjian in Song Dynasty once wrote in Shanggu Tiba that Transcript of the Orchid Pavilion is a satisfied work of Wang Youjun's. No matter how many times the work is being inspected and appreciated, not a single line or character is unsatisfied. If one tries to emulate his transcript, the writing in the copy would be whether too thin or too thick. There are also chances that imitators make their own styles and become experts. Thus, all its merits should be bore in mind and the beauty of them should be comprehended with heart attentively. Meanwhile, the handwriting of the Orchid Pavilion 
is featured with powerful and freely flowing characteristic, which is a unique and original style. Based on the calligraphic style of the Orchid Pavilion, Yu Wenhua combines distinctive musical tunes, sentence structures and melodies to compose the arrangements of the song Orchid Pavilion. This song begins with a relatively gentle tune and then alters into rather lively and cheerful style, which serves as a much suitable piece for dancing. And in the end of the song, repeated rhythm is used to corresponding the end and the beginning of each sentence pattern. Analyzing the massive structure of $\mathrm{Yu}$ Wenhua's Orchid Pavilion make the author clear about the overall melody of this piece, the melody magically expresses features of the handwriting including its size, density, leaning or standing straight, uneven setting, its length or width. Take the character “茂” for instance, the horizontal line on top of the nether part is joint together with the hook downside, and the right part of long horizontal line in “毕” is covered for another time when Wang turns back to write the vertical line in it, and the upright line with a minor lift in the word "长" is written with noninerruption after the long transverse line, and after he writes the transverse line in “宇”, Wang turns the writing brush upward and creates the vertical line with a minor corner of lift directly "Fig. 1".

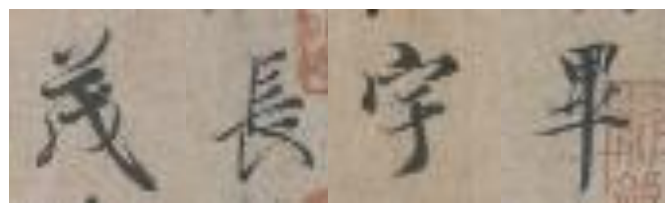

Fig. 1.

\section{B. Endowed with Feature of the Era, the Work Embodies Mellow and Vigorous Writing Style of the Transcript}

The independent expressing force of the rhythm is based on the tone of the music, breathe of the singer and other actions all together, and it in turn accurately manifests the nature of above activities. The tension of relaxation of rhythm may stimulate the resonance of listeners' inner thoughts with the music. Although the Orchid Pavilion of $\mathrm{Yu}$ Wenhua's version is a piece of music that is vigorous and energetic, she was filled with tears back in times of creating this song [3]. As is widely known that Wang Xizhi seems to wrote the Orchid Pavilion as the work is the description for enjoyable scenery of mountains and rivers surround the Pavilion, and the pleasant emotions of each intellectual and celebrity at the graceful party but as a matter of fact it is Wang's exclamation for the fugacious of life and capricious of death. He used strong and vigorous lines in the writing, for example the dot on top of the character “朗” is upturned and linked with the left falling stroke in “月”, and the left part of “快” is written firstly the two dots and then the long upright line. The central vertical line in “山” in character “湍” is connected with the lowest dot in the left part of the character. And then the short left falling stroke in “仰” is written in a vertical dot form firstly and then falls to the left as a sideling form. There is Yu Wenhua's exclamation for life and death and her longing for a bright future on the basis of the merry and cheerful tone of the whole music. Only if you fully comprehend that life is capricious, can you cherish present reunion. The handwriting of the Orchid Pavilion show the author's feeling of celebration for intellectuals and celebrities to the party with mellow figures and reveals his exclamation for life with strong and uptight lines "Fig. 2".

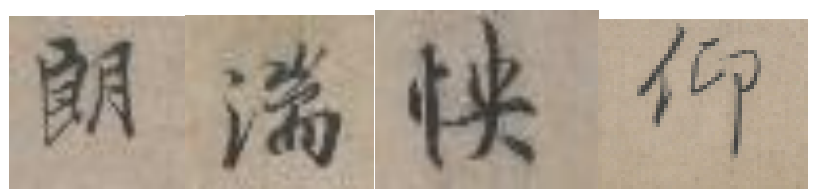

Fig. 2.

\section{Emphasis on Special Aria as Freely Floating Clouds and Flowing Water}

The Orchid Pavilion is a work that breaks away from writing style popularized in Han and Wei Dynasty, and combines the merits of $\mathrm{Li}, \mathrm{Cao}$, Kai and Xing and finally created its own technique.

Points and lines in calligraphy begin with sharp corners onto the paper, it impresses viewers with the feeling of characters flying against the current and soaring in the sky. Besides, the writing brush seems to move so swift that the lively and invigorating figures are created. Wang Xizhi is an expert in using Gou, Tiao and Qian to emphasis the connection between points and the whole picture, in order to realize the composition of a perfect combination of each dots and the whole scene with the flowing will and Qi. For example, the written form of “事”, “不”, “其”, “畅”, “兴”, “后”, “欣”, “今”, “为”, “揽”, “怀”, “以”, “所”, “仰” etc. In order to stress this unique and peculiar feature of the Orchid Pavilion, Yu Wenhua uses the technique of "Chenci" in creating the music, and hence paragraphs of lyrics with Chenci are more charming than the others. In addition, the Orchid Pavilion is called the most terrific handwriting under heaven for its whole structure, which can be compared with the floating clouds and flowing water. It sees that the work is composed in just one stretch. Hence Yu Wenhua's Orchid Pavilion connects diverse melodies through Chenqiang to adapt with the demand coming from its integral content.

\section{Expressing Sincere Feelings and Taking on the "Well- Proportioned"}

The Orchid Pavilion embodies Wang Xizhi's temperament, bearing, taste and sentiment, which is depicted by his sincere feelings. The above characteristics are well proportioned in the whole calligraphy, realizing the emotional elevation of the work [4]. Yu Wenhua appreciates the verve of the Orchid Pavilion. In the process of creation, Wang Xizhi emphasizes the control of lyric's melodies and he could associate the expression of feelings with the melodies, developing "impressive melodies and touching feelings", which elevates appreciators' spiritual realm and expresses Wang Xizhi's "temperament, bearing, taste and sentiment". 


\section{YU WENHUA'S MUSICAL ARRANGEMENTS ON THE ORCHID PAVILION}

Yu Wenhua attaches more importance on the feature of vocal music performance, especially for the consistence of melodies and variety of structures. The analysis on the musical arrangements is as following.

\section{A. Emphasis on Image Building Makes It Exquisite}

The overall feature of calligraphy of Orchid Pavilion is delicate, pretty, passionate and exquisite such as “峻”, “贤”, “至” etc. The three Chinese characters show very delicate and pretty. While the Chinese characters “盛”, “以”, “茂” etc are powerful and passionate. Combined with the features of Orchid Pavilion, Yu Wenhua creates distinguished image. As focusing on the sentiments in Orchid Pavilion, $\mathrm{Yu}$ pays attention to modern trend, modern style and wonderful mood. And then she adopts onomatopoeia, mimicry and shape imitation to enhance the creation of image in the song. Her onomatopoeia applies nature's sound and rhythm to deal with the work, combining tone and melodies, which is not only improving the music feeling but also constituting a good connection with different parts "Fig. 3".

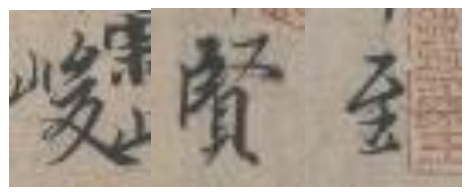

Fig. 3.

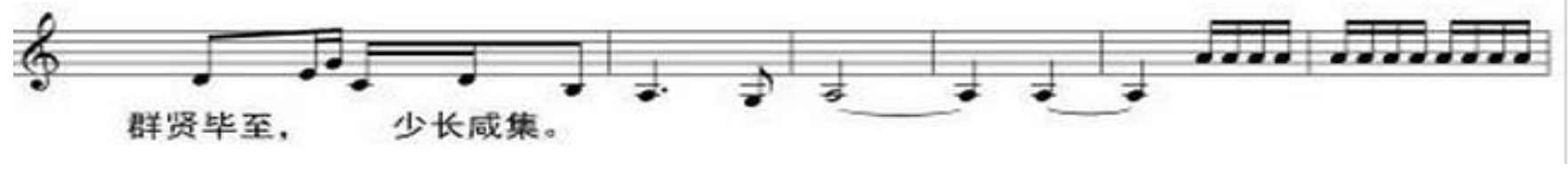

Fig. 4.

As shown in "Fig. 4", the easy and slow rhythm in the beginning and later on interlude use dominant to compose a soothing and consistent image. The singer should use lumboabdominal strength to keep breath smooth. Meanwhile, the artist should make the music heard melodious. In refrain part, the feeling of the music is strengthened by liners of imitating the tranquility around the Orchid Pavilion. In the same time, with repeated emphasis on the dominant, the Orchid Pavilion shows more characteristic, which successfully creates an image of all the people of virtue arrived. Audience could feel the jamboree to the joyous rhythm and temps.

\section{B. Sincere Emotion Expression with Virtual Reality}

The incentive of creating Orchid Pavilion is emotion. Sincere emotion could make music play use of unique charm. Such music could touch people's heart and arouse resonance. The sincere emotion could make the content of Orchid Pavilion elevated and make it take on rich feelings.

The song of Orchid Pavilion should be performed by a soprano. The pleasant melodies express the happiness of celebrities in the jamboree and show us the beautiful scene around the Orchid Pavilion. In the beginning of the song, the music adopts the prelude of triplet "Fig. 5" and gradual chord "Fig. 6" to enhance feeling expression of the Orchid Pavilion. In the process of performing, the artist should have signingstyle emotion to recite “永和九年, 岁在癸丑, 暮春之初, 会于会稽山阴之兰亭 (In the ninth year of the reign Yonghe(A.D.353), in the beginning of late spring we met at the Orchid Pavilion in Shanyin of Kuaiji)." "Fig. 7" In the middle of “暮”, when the stroke ends the “页” horizontally, the stroke goes back to original track till the middle part and continue to write the dot, so is the second horizontal stroke of “初”. This technique is not easy to recognize since there is no evident repeating stroke, while there is some linking hint between horizontal stroke and dotting stroke in the “阴”. Taking the beginning with soft tone would make people feel soft feelings, which would not lay a foundation of jamboree afterwards. The correct expression of emotion would be impacted with overdue cadence. Therefore, when processing the emotion of Orchid Pavilion, the singer should correctly control the emotion and precisely express the sincere emotion "Fig. 8".

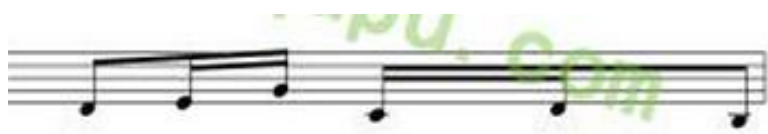

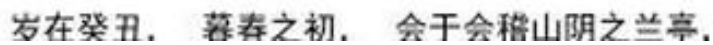

Fig. 5.

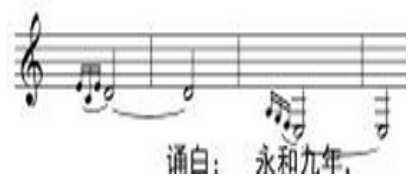

Fig. 6.

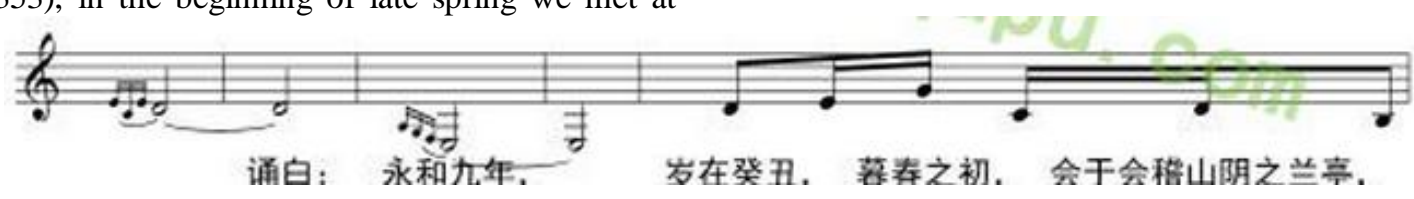

Fig. 7. 


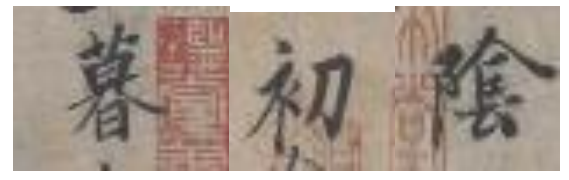

Fig. 8.

\section{Deducing the Character of the Song, Simple but Unusual}

When deducing the music composition, we could not make a superficial deduction just depended on the sign of labeled melody, but should learn about the multi-level emotions containing in the labeled melody. The Orchid Pavilion begins with easy chord. Writing the character “永”, the pen describe from the original line back to the middle vertical hook when the short transverse stylus. "岁" writes a skim after the crossing with a suitable pen, which is not out of the front. The Chinese character “会” skims to the left, writing the backslash inversely which is out of the front and then forms a rolling writing style. It makes people reminding the peace of the Orchid Pavilion, and the scene of birds' twitter and fragrance of flowers will be slowly in sight "Fig. 9".

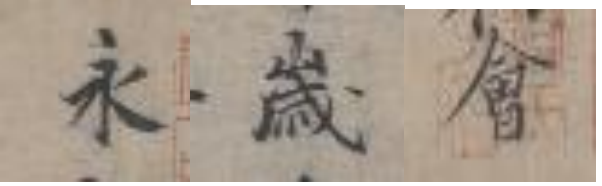

Fig. 9.

Then the melody of scene contains rich rhythm, and the style of monologue is adopted in the music, which make the musical image of the character “岁”, “春” and“稽” much brighter and more cheerful "Fig. 10". It will be formed a illusion that celebrities are holding a happy get-together, which makes audiences generate a impulsion that they want to take part in it.

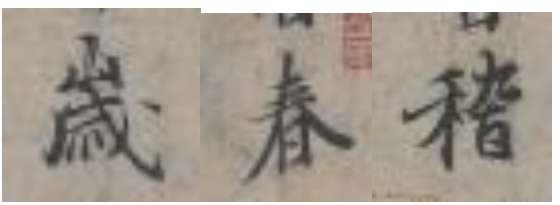

Fig. 10.

The Orchid Pavilion begins with the upbeat, which makes the audience produce the sense of dynamic and generate the lively and emotional feelings on the psychological. The music adopts the style of monologue, which makes the song more cheerful. In the Orchid Pavilion, the character “领”, “竹”, “清”, "以" is written by the means of running hand, regular script, grass writing and other calligraphic versions. The tilt in the left and right, and the jump in the up and down gives a person an apparent sense of multi-levels. So when singing the song, we should pay attention to the expression of emotions, and layer the song through singing in the long tones. The long tones can lie an underneath for the back climax, forming a progressive power of layer upon layer. The melody of ups and downs in the Orchid Pavilion promotes the expression of emotions and contains the exclamation for the fugacious of life and capricious of death. As shown in the "Fig.11".

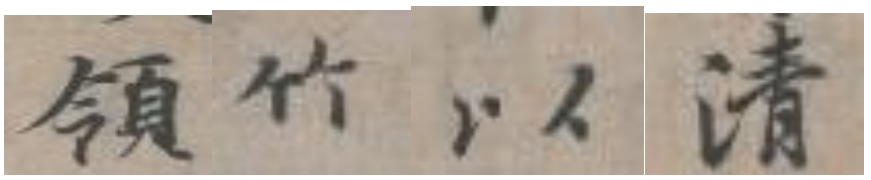

Fig. 11.

\section{CONCLUSION}

$\mathrm{Yu}$ Wenhua opens up a way of national music on the basic of absorbing the successful experiences of predecessors. She endows the Orchid Pavilion with characteristics of the times, using her abundant accumulation of national music and mastery of creative skills. Yu Wenhua makes a further study of the writing background of the Orchid Pavilion to find the emotion of Wang when creating. Yu pays attention to the description of the natural surrounding of the Orchid Pavilion, and show the expression of Wang's reflection on her life. Her aesthetic orientation determines the features of her music creation: nationality, modernity and popularity, which makes the national music suit both refined and popular tastes. The music work of Orchid Pavilion is a Yu Wenhua's masterpiece in the national music creation, and is also a moving melody left for the era, which creates the calligraphic masterpiece in the Eastern Jin Dynasty into a modern national music.

\section{REFERENCES}

[1] Wang Lin. Appreciation on Orchid Pavilion of Wang Xizhi [J]. School Art Education, 2013, (7):33-34

[2] Liu Minglan, Ancient Chinese Poetry Music [M] Shanghai: China Science and Culture Press, 2003,4-109.

[3] Long Qiang. Vocal Music Grading Tutorial of Series Textbooks of National Normal Colleges[C]. Beijing: Central Conservatory of Music Press, 2013.

[4] Yuan Ming. Ancient and Modern Lyrics Form the Soul of a Nation Review on No Instruments Chorus of Peach Blossom Fan [J]. People's Music, 2010,(5):12.

[5] Wang Zhongyu. Singing Style of Chinese Chorus Music Works [J]. Journal of Anhui Normal University (Humanities and Social Science Edition), 2007,(2):72

[6] Cheng Bingjie. Transformation of European Chorus Aesthetic Model from Classical to Romance $[\mathrm{J}]$. Journal of Anhui Normal University (Humanities and Social Science Edition), 2010,(3):212. 